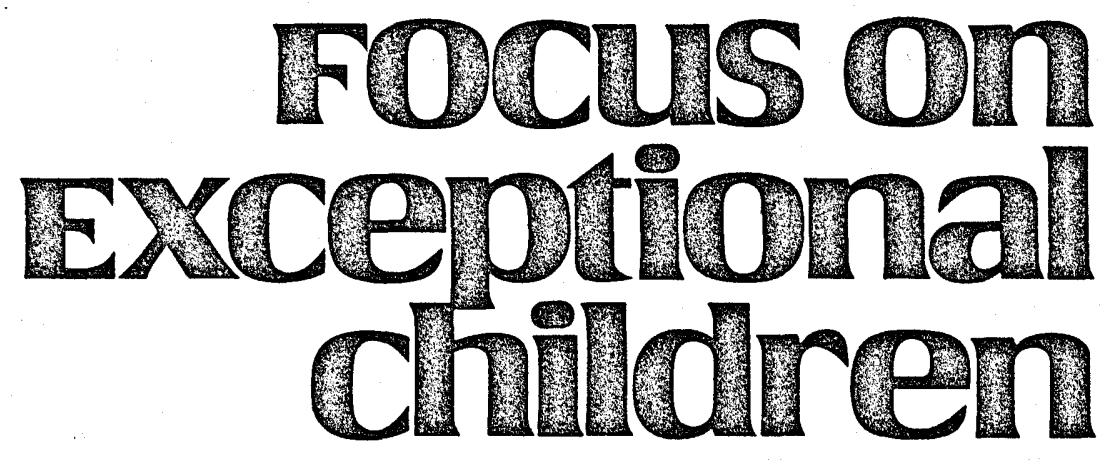

\title{
Cognitive-Behavioral Training in the Curriculum: Time, Slow Learners, and Basic Skills
}

\author{
Michael M. Gerber
}

Whatever disagreement exists concerning identification of various subtypes of mildly handicapped $(\mathrm{MH})$ learners, a consensus probably exists that these students learn at a slower rate than do their normally achieving peers. The idea of "slower rate" implies managerial as well as cognitive-behavioral concerns. In part, slower rate of acquisition is a function of discrepancies between time allocated by teachers for learning and time during which $\mathrm{MH}$ students are cognitively engaged with the content of learning tasks (i.e., academic learning time). MH students may be more predisposed to exhibit "off-task," or inappropriate task orientation, behaviors than their normally achieving peers. These students quite literally "waste" time, presenting teachers with difficult management problems.

If task orientation behaviors were the only problems, however, academic gains for these students should be obtainable simply by increasing the percentage of allocated time that they appear to be actively engaged in learning. In fact, this line of reasoning has led to many intervention strategies that have sought to increase the probability of "on-task" behaviors through use of adult managed (e.g., see Kauffman \& Hallahan, 1979) or student managed (e.g., see Hallahan \& Sapona, 1983) procedures.

Another line of thought-one for which practical implications are less well researched in special education-holds that even under conditions of optimal attentional behavior during tasks, MH students are always "slower" learners because they have difficulty allocating attention efficiently to information within tasks. (For general discussion of evidence favoring an attentional deficit hypothesis, see Hallahan \& Reeve, 1980; for contrary evidence and arguments, see a recent paper by Samuels \& Miller, 1985). If this hypothesis is true, $\mathrm{MH}$ students, under available conditions of instruction, will require absolutely more learning time than faster learning peers if they are to develop similar levels of mastery and automaticity. Therefore, slower rates of acquisition present instructional design, as well as general managerial, problems.

Michael Gerber is an Associate Professor of Special Education, University of California, Santa Barbara. 
Further, if observable amounts of task engagement are only a general consequence of variable degrees of cognitive efficiency, the reason that measures of time on-task correlate only moderately and inconsistently with achievement measures, and why some students invariably "need differing amounts of time to achieve the same learning goals" (Karweit \& Slavin, 1981, p. 171), becomes clearer. Unfortunately, special education has no well developed theories that relate macro teaching and management variables (such as allocated learning time, instructional grouping, and instructional design) to within-student, cognitive or micro variables (such as coding, strategy generation, and structure of knowledge). By discussing how cognitive-behaviorial training methods might facilitate acquisition of basic skills in $\mathrm{MH}$ students, this article is intended as a step in this direction.

\section{THE GENERAL EDUCATION DILEMMA}

Recent work by Gettinger and her colleagues has renewed interest in and brought fresh perspective to the role of time in classroom learning. A study by Gettinger (1984a) supports the hypothesis that the ratio of time spent in learning (TSL) to time needed to learn (TTL) for normally achieving students is a reliable predictor of achievement, whether measured by criterion task accuracy, retention, tested achieve-

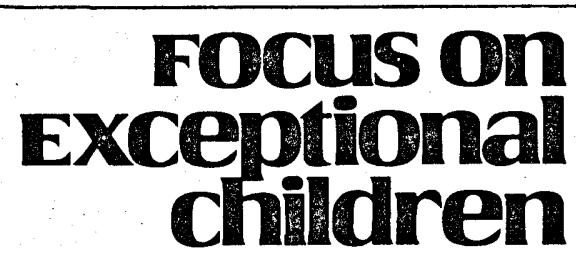

FOCUS ON EXCEPTIONAL CHILDREN (ISSN0015-511X) (USPS 203-360) is published monthly except June, July, and August as a service to teachers, special educators, curriculum specialists, administrators, and those concerned with the special education of exceptional children. This journal is abstracted and indexed in Exceptional Child Education Resources, and is also available in microform from Xerox University Microfilm. Ann Arbor, Michigan. Subscription rates, $\$ 18.00$ per year. Copyright $\odot 1986$, Love Publishing Company. All rights reserved. Reproduction in whole or part without written permission is prohibited. Printed in the United States of America. Second class postage is paid at Denver, Colorado.

POSTMASTER: Send address changes to:

$$
\begin{gathered}
\text { Love Publishing Company } \\
\text { Executive and Editorial Office } \\
1777 \text { South Bellaire Street } \\
\text { Denver, Colorado } 80222 \\
\text { Telephone (303) } 757-2579 \\
\text { EDITORIAL BOARD }
\end{gathered}
$$

Edward L. Meyen

University of Kansas

Richard J. Whelan

Glenn A. Vergason Georgia State University

University of Kansas Medical Center
Stanley F. Love Publisher
Carolyn Acheson Senior Editor ment, or teacher ratings of performance. Moreover, Gettinger and White (1979) showed that the TSL:TTL ratio was a more adequate predictor of task-specific learning than IQ for elementary students of normal intelligence. When TSL was student determined, Gettinger and Lyon (1983) found that about two-thirds of the variability in discrepancies between TTL and TSL in a sample of boys exhibiting classroom behavior problems could be accounted for mostly by prior achievement and a combination of variables related to attention, including level of interest, locus of control, and selfconcept.

These findings suggest a spiral of transacting events in which insufficient time to learn on earlier occasions increases the need for learning time in the present. Inadequate acquisition of basic skills and critical knowledge, as a function of insufficient learning time, results in a cognitive-behavioral status that requires progressively more time to learn hierarchically more difficult material on future occasions.

If classroom learning time is viewed as a scarce and relatively fixed resource, interventions based on differences in time needed to learn require strategies directed not only toward learners but also toward time constraints inherent to classroom teaching. Ideally, interventions must acknowledge and address in an integrated fashion the overt behavior-covert cognition dualism associated with "slow" rates of learning (Gerber, 1983). That is, MH learners exhibit overt learning behaviors that, though sometimes discernibly different, similarly restrict them to less than best use of available learning time.

Moreover, salient learning characteristics of MH students, however variable for defined subgroups, also appear to be related to some level of cognitive inefficiency. Therefore, even if intervention strategies successfully induce all of the behavioral concomitants associated with "attention to task," the typical amounts of time allocated for classroom learning still will be insufficient to assure rates of acquisition for some $\mathrm{MH}$ students that are equivalent to acquisition rates of their normally achieving peers.

From a purely pragmatic perspective, without trying to disentangle characteristics thought to be diagnostic of discrete handicapping conditions, MH students can be expected to (a) take longer to reach the same achievement criteria as set for their classmates, and (b) require more instructional effort or more powerful instructional techniques, or both. These expectations have important implications for various approaches to mainstreaming, but especially for what is being called the "general education initiative"-a set of recent policy proposals aimed at increasing the role of regular classrooms and teachers in the education of many or most students now classified as mildly handicapped (Will, 1986). From a policy, or macroanalytic, perspective, these implications should be considered with reference to two "laws of motion" operating in all classrooms. 


\section{The Law of Time-Achievment Exchange}

Teachers in typical classrooms can control time or achievement, but not both. If they fix the amount of time that they will teach toward some particular instructional objective, achievement as a function of individual differences will vary. On the other hand, if teachers attempt to fix achievement, time needed as a function of individual differences likewise must vary.

\section{The Law of Distributed Outcomes}

Teachers can try to maximize the mean level of achievement for the class as a whole, or they can attempt to minimize variability of learning outcomes. If instructional resources (and technology) are assumed to be relatively fixed, however, they cannot do both. This means in practice that instructional effort will result either in smaller differences between slower and faster students at the end of a specified instructional period or in greater differences (i.e., greater mean outcomes) driven by achievement of faster students.

These "laws" continually force teachers to decide whether to continue investment of instructional time and effort in $\mathrm{MH}$ students who have not yet obtained mastery of some objective, or to reallocate their time to begin instruction toward mastery of new objectives by more modal students. As long as individual students differ from one another in instructionally meaningful ways, these laws will generally hold, regardless of how students are classified or instructionally grouped. Obviously, these laws constantly tend to operate to the disadvantage of $\mathrm{MH}$ students being taught in mainstream settings.

Although some empirical evidence (Brown \& Saks, 1984) suggests that teachers tend to choose variance-reducing teaching procedures (presumably by directing instructional effort toward lower achieving students), studies of teacher decision making tend to support the view that teachers, as a cognitive convenience, prefer to direct instruction to the large middle group of students in their classes (e.g., see Shavelson \& Stern, 1981).

Being able to transfer instructional responsibility for their most difficult students to a subsystem such as special education helps teachers accomplish both these objectives (Gerber \& Semmel, 1985). By removing these most difficult, time consuming students, teachers instantly achieve smaller class achievement variances and increase the number of students falling into an instructionally tractable modal range. Therefore, attempts to maintain effort-demanding, slower-learning students in regular classrooms without either increases in critical teaching resources or implementation of new, more powerful instructional technologies will yield inevitably disappointing results. A relentlessly growing gap between achievement and age can be expected to develop, coupled with an ever decreasing amount of public school time remaining. The consequences are high rates of referral to special education and a burgeoning number of students classified (Gerber, 1984a); and high rates of drop-out or "push-out" (Zigmond \& Thornton, 1985) of MH students invariably result.

\section{THE NEED FOR NEW APPROACHES}

What appears to be needed is a new approach to curriculum that encourages instructional efficiency in how teachers allocate and use available time, but also cognitive efficiency for learners depicted as "slow" relative to a modal group of peers. This approach requires both a theoretical and practical integration of variables arising from cognitivebehavioral research as well as from classroom instructional research.

\section{Implications of Cognitive-Behavioral Research for Classroom Instruction}

Several recent reviews have attempted to integrate cognitive-behavioral intervention research and draw suitable implications for practice (Corno \& Mandinach, 1983; Doyle, 1983; Frederiksen, 1984). In trying to understand "cognitive engagement," for example, Corno and Mandinach (1983) viewed students as:

. . . actively engaged in a variety and range of cognitive interpretations - of their environments and themselves-which, in turn, influence the amount and kind of effort they will expend on classroom tasks. (p. 89)

"Cognitive engagement," therefore, represents processing of task-specific information but also, and simultaneously, some degree of cognitive self-regulation. This self-regulatory component minimally includes deliberate planning and monitoring during performance of academic tasks. The actual degree of self-regulated learning, however, also reflects the degree to which "some of the processes are overtaken by classroom teachers, other students, or features of written instruction (p. 89)."

It follows that, while academic "tasks" are the natural and basic units of classroom learning.(Doyle, 1983), teachers are able to adjust the cognitive demands implicit to different types of school tasks for learners differing in maturity and ability by varying the directness of instruction. Presumably, slow or immature learners are assisted cognitively when instruction is "direct." Doyle (1983) asserted that learning "procedural" or "routine" tasks (e.g., computation, decoding) is particularly facilitated by direct instruction in specific solution algorithms (p. 177). He described procedural tasks-what teachers might recognize as "basic skills"-as those that can be performed "without understanding by sim- 
ply knowing how to follow a series of computational steps," while what he called "understanding tasks" requires "knowledge about why the computational steps work (p. 165)."

\section{Cognitive Elements within Direct Instruction}

The power and conceptual simplicity of methods collectively known as "direct instruction" procedures have achieved a rough consensus among researchers about teacher behavior variables that are critical for effective instruction of students with mild handicaps (Good, 1983; Rosenshine, 1983; Stevens \& Rosenshine, 1981). Generally speaking, techniques derived from these pragmatic, interventionoriented perspectives emphasize active effort by the teacher to elicit as many correctable or reinforceable responses from students as possible within instructional time constraints. Moreover, these techniques typically require careful attention to the amount and type of environmental structuring necessary to assure controlled and consistent student achievement, especially for simple, delimited, academic responses. Some of the features of this structuring include:

- Grouping by immediate instructional needs.

- Careful sequencing (programming) of academic skills to be taught.

- Modeling.

- Rapid pacing to achieve high-density response opportunities.

- Use of response signals to control attention and pace.

- Use of choral as well as independent responding.

- Immediate corrective feedback, including adequate, contingent reinforcement.

- Ample, monitored practice.

The literature contains ample demonstration and review of the power, utility, and broad applicability of these techniques for all aspects of curriculum and across a range of learner characteristics (e.g., Becker, 1977; Becker \& Carnine, 1981; Carnine, 1983; Engelmann, 1969; Lloyd, 1975; Lloyd, Cullinan, Heins, \& Epstein, 1980). Therefore, they will not be discussed further here. It is necessary to point out, however, that successful demonstration of these and related active, or "hot," teaching techniques, particularly with students presumed to have mild handicaps, generally has not been derived from theoretical models of learning specific to exceptional children. Cognitive processes are subsumed for teaching under one of three categories of knowledge: (a) basic concepts ("forms"), (b) relationships ("joining forms"), and (c) cognitive "routines" (Carnine, 1983, p. 23). Although Becker (1977) and Carnine (1983) have argued that there are cognitive as well as behavioral reasons for the observed effectiveness of direct instruction procedures, application in practice has been largely atheoretical and relegated by some to the status of an engineering problem.
Specifically, teachers are advised to control events that have empirically demonstrated relationships to desirable child outcomes. No insight into individual differences among learners is considered necessary. Instead, there is a conscious pragmatism in selecting techniques that are so economical and potent that reliable-though perhaps not optimal-gains are achieved independent of individual differences. Consequently, it has become common to treat these techniques as instances of "good" or "effective" teaching, without analysis of how, as educational treatments, they may uniquely interact with specific learning characteristics (i.e., aptitudes) of students prone to be identified as mildly handicapped. Some students, however, require little more than a verbal hint, while others require the full panoply of highly structured techniques to acquire the same knowledge or display the same level of skilled behavior.

More strictly behavioral versions of direct instruction regard basic academic skills as presenting problems of instructional, not learner, strategy. Researchers working in this tradition attempt to specify "procedures needed to teach general cases and to cumulatively build knowledge within sets of related concepts (Becker, 1977, p. 531)." This approach avoids becoming tediously additive because it:

$$
\begin{aligned}
& \ldots \text { seeks to identify the smallest set of rote memory items and set } \\
& \text { of rules for combining these items that will provide skills for attacking } \\
& \text { problems of a given type while also developing the basis for attacking } \\
& \text { related problems. (Lloyd et al., 1980, p. 11) }
\end{aligned}
$$

\section{Invention and Problem Solving}

Learners, even handicapped learners, are never really cognitively passive during tasks requiring even simple algorithms. Rather, young and cognitively immature learners can be observed engaging in a form of problem solving as well as simple retrieval of task-specific knowledge. For example, work on young children's early spelling by Read (1975), Henderson and Beers (1980), and Bissex (1980) demonstrates that normally achieving students progress through a series of predictable stages actively struggling to induce the rule system of governing spelling. Gerber (1984b), Cook (1981), and Bookman (1984), for example, have shown that similar, though lagged, developments can be observed in students described as dyslexic or learning disabled.

These studies showed that students, whether novice or handicapped, naturally attempt to induce or "invent" rule systems to simplify and economize cognitive effort while learning how to spell. Error making during these natural problem solving attempts tends to be systematic rather than random, representing incomplete knowledge or inefficient algorithms rather than absence of knowledge and rote memorization.

Unfortunately, despite their being naturally inventive in 
problem solving academic tasks, teachers cannot depend upon the ability of slow learners to induce basic algorithms that are optimal, durable, or flexible unless additional instruction is provided in "higher level executive control processes and knowledge structures for representing tasks and selecting solution strategies (Doyle, 1983, p. 178)." This caution implies a need for teaching general as well as taskspecific problem solving procedures, where how to coordinate and effectively use task-imposed, teacher-arranged, and learner-generated "structure" is the general "problem" to be solved.

Following Simon (1973), Frederiksen (1984) noted that "novices" seeking to acquire expertise in a field of knowledge are confronted by two classes of problems-well-structured and ill-structured problems. Well-structured problems generally are those for which a necessary and sufficient set of explicit algorithms can be stated, taught, or induced. Ill-structured problems, on the other hand, do not provide such unambiguous or even stable instructional targets. To solve the latter problems, learners or teachers must contrive some structure where there appears to be none. Short of some sudden, inexplicable insight, novices must repeatedly practice elements or procedures associated with these problems until a relative automaticity in performing some component operations develops, thereby freeing attentional resources for manipulation of less tractable components.

Analogously, response demands associated with tasks meant to train "basic skills" pose "problems" that are illstructured from the perspective of immature or slow learners. In early stages of acquisition, demands for elemental responses involving, for example, recall and manipulation of sound-symbol or number-numeral associations similarly require repeated practice until some response components are sufficiently automatized to allow attention to other components, or to problems of application such as composition in writing, word problems in arithmetic, or comprehension in reading. How teachers design and manage tasks to teach skills underlying these applications can increase or decrease the "structure," and, hence, the cognitive burden for learners.

Nevertheless, a "brute force" approach to teaching these skills has been most common. This approach typically involves repetitive practice to induce rote memorization. For normally achieving, or modal, learners, naturally inclined to be self-organizing and self-regulating, this approach is economical because these students tend to spontaneously and rapidly generate facilitating problem solving approaches, and having mastered "basic" knowlege, they soon are able to attack tasks requiring its deliberate (i.e., skilled) application, such as writing sentences, reading passages, and higher level computation.

\section{Limitations of "Brute Force" Approaches For Mildly Handicapped Students}

For MH students, unlike most learners, "brute force" learning does not come easily. First, they often fail to spontaneously generate sufficiently powerful or reliable memorization strategies. Second, they often require more time than their normally achieving peers to practice to increase both accuracy and speed of performance to desirable levels. Third, and perhaps most important, they often do not know why they are memorizing the information, in what context it is meaningful, or how to internalize the "structure" provided implicitly by teachers as part of task design and instructional presentation.

Failure to develop proficiency in fundamental skills is one of the factors that works to the cumulative disadvantage of MH students, in terms of specific content mastery as well as in terms of their perceived teachability by classroom teachers. At the microanalytic level, failure to become proficient in basic academic skills contributes to generalized and cumulative deficiencies in both knowledge and ability to cognitively manage higher order academic tasks. At the macroanalytic level, the classroom presence of students who are unable to use basic academic skills accurately and rapidly contributes to teachers' perceptions that some students are absolutely unresponsive to conventional methods of instruction offered in regular class environments. Perceptions like these ultimately decrease teachers' willingness to invest much additional instructional effort in "slower" students and concomitantly increase the probability that these students will be referred for "special" education as "handicapped."

What is the solution? Probably, training of generic problem solving ability must begin in parallel with teaching of basic skills, not only to facilitate acquisition of these skills, but also to establish patterns of conscious attention to the generic aspects of "executive work" common to all problem solving situations. To accomplish the latter goal, basic skills learning has been described as an early and prototypical type of problem solving for which a growing body of cognitive-behavioral training (CBT) literature may have great relevance.

\section{ELEMENTS OF COGNITIVE BEHAVIORAL TRAINING}

Despite conceptual fuzziness and confusion over ill-defined samples of mildly handicapped learners, the past decade has seen a promising shift to more instructionally oriented special education research. Some of this research in particular appears to combine elements of cognitive theory and behavioral technology into what might be labeled generically as cognitive-behavioral training (CBT) intervention models. When focused on applied academic tasks and classroom performance rather than laboratory analogues, this growing body of work has intuitive appeal for many practitioners. The formal requirements for conducting instructional reseach (e.g., see Belmont \& Butterfield, 1977; Cohen $\&$ deBettencourt, 1983) have encouraged reseachers to pro- 
vide extensive and explicit descriptions of instructional methods and techniques. Unlike much special education research literature, these descriptions present teachers with an unusually accessible and potentially rich source of practical information about how to systematically integrate cognitive-behavioral and content goals.

Furthermore, if use of CBT methods results in greater capacity for self-management of learning, as its proponents claim, the perceived "teachability" of MH students by classroom teachers should increase, which in turn should increase the willingness of teachers to invest instructional effort in MH students regardless of classroom setting. The past years have seen CBT-related methods applied increasingly and with generally encouraging results to both differentiated and nondifferentiated groups of students whose shared, common characteristic is that of poor and cumulatively worsening responsiveness to conventional methods of instruction.

Therefore, special education research on various approaches to and targets for use of CBT methods with mildly handicapped students has burgeoned. Reviews of experimental findings and speculations about their implications for special education have appeared in unusually rapid succession (e.g., see Abikoff, 1979; Harris, 1982; Rooney \& Hallahan, 1985; Sheinker, Sheinker, \& Stevens, 1984). Although CBT has not been viewed as a method for enhancing acquisition of basic skills, it not only might prove useful for facilitating acquisition of basic skills but also might provide a model for conceptualizing a truly "special" education curriculum that would address rate as well as content of learning problems for those described as mildly handicapped.

Although few studies have attempted to use CBT methods directly to facilitate acquisition of basic skills, several studies would appear to provide fertile ground for elaboration and experimentation because they have (a) attempted a cognitivebehavioral intervention directly, (b) used some form of explicit, direct instructional method that provides cognitive "structure," or (c) conducted analyses of cognitive components reflected in task performance (e.g., reading: Bos, 1982; Carnine, 1983; Samuels, 1979; Frederiksen, Warren, \& Roseberry, 1985; Palincsar \& Brown, 1984; Pflaum \& Pascarella, 1980; handwriting: Graham, 1983; Kosiewicz, Hallahan, Lloyd, \& Graves, 1982; Robin, Armel, \& O’Leary, 1975; spelling: Bissex, 1980; Bookman, 1984; Farnham-Diggory \& Nelson, 1984; Frith, 1980; Gerber, 1984b, 1984c, 1985, in press; Graham \& Freeman, 1985; Lovitt, 1975; Nulman \& Gerber, 1984; composition: Ballard \& Glynn, 1975; Harris \& Graham, 1985; arithmetic: Baroody, 1984; Carpenter, Moser, \& Romberg, 1982; Cullinan, Lloyd, \& Epstein, 1981; Grimm, Bijou, \& Parsons, 1973; Lloyd, 1980; Lloyd, Saltzman, \& Kauffman, 1981; Lovitt \& Curtiss, 1968; Russell \& Ginsburg, 1984).

Some non-trivial theoretical and empirical issues remain to be resolved while research proceeds in this direction.
Most researchers have viewed CBT as a means for facilitating organization of previous knowledge or behaviors into a more efficacious problem solving routine (e.g., see Brown, Campione, \& Day, 1981; Palincsar \& Brown, 1984). Because higher order academic tasks, such as reading comprehension, are typically targeted, extensive pretraining has been necessary before CBT can be effectively applied. But an unwarranted tendency has been to dismiss CBT techniques with younger students because of assumptions about their cognitive immaturity and lack of basic knowledge. This remains, in the author's judgment, an empirical question. Moreover, MH students, unlike their normally achieving younger peers, have accrued considerable (though perhaps inadequate) declarative and procedural knowledge about academic tasks.

Regardless of whether CBT procedures will prove successful with younger students, more intensive and systematic research on CBT training of basic skills with MH students seems desirable. Specifically, opinions held by some researchers that CBT is effective chiefly as a means for enhancing on-task behavior during independent practice or other drill activities require further exploration. Some have speculated, for example, that CBT:

... works best when children are working on tasks for which they
already have the skills. We are skeptical about how successful the
procedure would be for children when they are in the acquisition
stages of learning. (Hallahan \& Sapona, 1983, p. 619)

The approach associated with this latter opinion has been well documented by Hallahan and his colleagues at the University of Virginia Learning Disabilities Research Institute since 1979 (Hallahan et al., 1983). LD students selected on the basis of their observed distractibility, and trained to self-monitor and record their attention, subsequently showed marked and reliable improvements over baseline in attention to task. Moreover, they showed consistent gains in academic "productivity" (number of observable, correct or appropriate responses per minute), leading to the logical inference that observed changes in "attention" were associated with desirable cognitive activity and not merely its behavioral concomitants.

Nevertheless, the inference that self-monitoring training of this type might have to be restricted to overt attention difficulties during practice of known responses presents some conceptual and practical disappointments. First, were it true, it certainly reduces the breadth of application of the technique, however easy to implement, for helping students acquire new skills. It might be argued that increasing cognitive engagement during drill makes use of that time more efficient, thereby "freeing" time for direct instruction of new skills. Presumably, though, during instruction of new material, students would be as difficult to teach, relative to their normally achieving peers, as ever.

Positive changes in overall efficacy of instruction would 
seem not to be strongly influenced by use of the CBT methods in this case, if at all. Self-regulation of the kind and quality expected from normally achieving students would be only partially achieved; successful learning would still depend more on externally provided structuring, as opposed to internally controlled processing, of information. A dependency on external structure, in turn, is part of what makes teaching slow learners effortful. Hallahan and his colleagues recognized this problem and have suggested that "a more curriculum-oriented view is warranted (Rooney \& Hallahan, 1985, p. 49)."

For example, Gerber and Niemann (in preparation) recently have applied CBT methods similar to those used in Virginia's attention self-monitoring studies in a multiple baseline design to train a distractable LD student to monitor the quality of his performance, rather than his on-task behavior, on three tasks: reading comprehension, listening comprehension, and expository writing. The self-monitoring question used in previous work ("Was I paying attention?") was replaced with questions for each task that specifically directed "attention" to the criterion performance expected after each task ("Will I be able to answer the questions at the end?" "Am I checking capitals, punctuation, and spelling?"). In addition, to test Hallahan and Sapona's speculation that CBT would not be useful at acquisition stages of learning, the student was provided difficult materials judged to be at his instructional level-not practice material.

Results indicated improvement above levels achieved at baseline or during reinforcement on measures of reading comprehension and writing accuracy in addition to increases in on-task behavior. Relative failure of listening comprehension to show meaningful improvement was interpreted to mean that the verbal self-monitoring induced by training was itself distracting during a listening activity. The findings from the other two tasks, however, were interpreted as indications that CBT could enhance performance on difficult material in which responses were still uncertain and problematic. Moreover, increased on-task behavior was obtainable without the necessity of directly training self-monitoring of on-task behavior. That is to say, when CBT was used to induce attention to the problem solving nature of difficult material, the behavioral concomitants of "on-task behavior" logically followed.

From a macroanalytic perspective, though these findings give reason to hope for application of CBT methods beyond independent practice, the question of learning rate remains. Are $\mathrm{MH}$ students to be taught individual skills in a more or less linear fashion in hopes that greater generalized competence will emerge from a sufficiently large repertoire? Stated differently, can a qualitative shift in learner competence be expected to occur as a function of incremental changes in the number of discrete skills acquired? Or, similar to Zeno's paradox, is there an infinity of definable skills, or subskills within skills, to be learned, making it practically hopeless to tailor some new version of CBT for each item in the curriculum?

There appears to be no escaping the need for a decision on how to apportion time between directly teaching what students must learn and teaching them more general means for approaching some class of academic tasks more effectively. Some researchers, such as Ann Brown (e.g., see Brown et al., 1981, p. 14) remain optimistic that CBT can contribute to both specialized and generalized ability. Nonetheless, as suggested by experiences of Hallahan and his colleagues in Virginia (e.g., Rooney \& Hallahan, 1985), one time, highly focal interventions, however successful, will have to be rethought in terms of ongoing curriculum.

\section{CBT Effects on Knowledge Search And Structure}

Whether approached from a cognitive or a behavioral perspective, CBT improves organization of task response. By providing a self-managed problem solving routine, the information load (or "problem space") associated with even basic skills tasks is reduced to more manageable proportions. If mildly handicapped students can be taught to approach learning tasks in a more structured, organized fashion, it is reasonable to expect that they also will be more efficient. This is because "structure," as Hall (1980) has noted, implies organization.

Structure also implies a transactional relationship between operations devoted to searching a knowledge base for relevant information and the structure of that knowledge base. For example, how quickly and efficiently one can reduce uncertainty by using what is known may determine to some degree both the reliability and future accessibility of newly appended knowledge. Conversely, the degree of organization with which knowledge has accumulated in the past may severely constrain the possible speed and efficiency of search procedures when confronting learning problems in the present.

To the extent that trained "strategies" impose structure by controlling information organization and sequencing, as well as timing and rate of response demand, to define "strategies" as overt behaviors or as internalized, cognitive processes is a matter of pedagogical indifference. Again from the teacher's standpoint, when understood in this sense, teaching clearly can be optimal or suboptimal for different learners. For mildly handicapped students particularly, effective teaching, like direct instruction, provides highly constraining structure that serves as an environmental proxy for absent or ineffective "strategies."

Although CBT might be viewed as useful only "as needed" whenever task performance roadblocks are confronted, however, to impact rate and quality of acquisition over time, CBT should be a formal part of the everyday curriculum. This, in fact, has been suggested (Borkowski \& Cavanaugh, 1979; Borkowski \& Konarski, 1981). The puzzle, from both 
a theoretical and applied point of view, has been whether there is, or could be, a simultaneous means of approaching specific and general learner competence that respects both individual and content differences but also can be implemented with reasonable economy of time and effort in real classrooms.

This type of approach will not likely take the form of single, elaborate intervention late in the elementary school career of most mildly handicapped students. More logically, the approach would have to be systematically associated with the curriculum that intends to impart basic academic knowledge and skills-parallel in a sense to the way in which teachers attempt to subtly embed instruction in schoolappropriate, task orientation behaviors (e.g., following directions, being alert to learning cues, beginning and ending tasks on time, proper use of tools/materials) in most primary grade lessons.

What would be novel in using CBT throughout the early curriculum, however, would be making the "hidden" portion of the curriculum that deals with problem solving and task management more overt and more potent for slower learners. Normally achieving students, or those who will be considered normally achieving in later grades, internalize useful and generalized task handling routines after relatively short exposures to teacher-imposed or task-imposed structure. From the teacher's perspective, their dependable ability to divide attention between information within the task and information about the task makes them easier to teach.

Behaviors indicative of developing self-regulation in early learning are subtle, however, as is their relationship to success and speed of acquisition. Because faster learning students appear to be so responsive to instruction, the critical role of mediating student behaviors often is overlooked or appreciated as an undifferentiated part of what causes these students to seem so "teachable." Unless their relevance in the teacher-learner system is recognized, teachers do not formally adopt CBT-type methods for directly developing or exploiting these behaviors more fully in slower learning students.

Consider, for example, normally achieving 6-year-olds who enter first grade and encounter what Doyle (1983) has referred to as "academic work" for the first time. Behaviors that they have only observed and imitated before, such as writing letters, decoding written words, and adding quantities, now are explored with interest, enthusiasm, and concentration. But now they also are required to complete a series of "tasks" that, independent of any innate attractiveness, require intentional remembering, purposeful comprehension, deliberate and facile retrieval and use of both declarative and procedural knowledge, and practice of selected responses until some standard of mastery is achieved. Even casual observation of these students strikingly reveals behavioral signs of emerging metacognitive capacity in parallel with their processing of task-specific information.

To illustrate, in addition to performing the components of any required response, one "average" first grader recently was observed to comment to herself (and to any available adult audience) on things she noticed about her own performance on a variety of ordinary paper-and-pencil letter tasks requiring simple decoding, letter writing, and simple addition. These comments sometimes were limited to labeling the behavior in relation to salient features in the stimulus field but also included comments that clearly represent early efforts to construct a self-regulatory transaction between task-specific information and meta-awareness of "self-engaged-in-task." Her comment and motor responses flowed with a continuity, intention, and rhythmicity. This is not to say that she never was observed to be "off-task." Most of the self-talk, however, was clearly task-related. Her comments never appeared to punctuate a series of pencil responses so much as glue them together, serving a variety of functions such as:

- Schematizing-recognition of analogies between some aspect of the task and previous experience or knowledge; e.g. (reading), "This word has /E/ sound in it just like ..."

- Self-Monitoring - statements or behavior interpretable as indication of planfulness, error consciousness, and attempts to control impulse; e.g. (writing), "Oops. I made a mistake." . . . "I'm being very careful, aren't I?"

- Strategizing-discovery or invention of algorithms or rules for reducing response uncertainty; e.g. (adding), "First you say this number, then you hold up that many fingers, then you ...."

- Recruitment-bids for reinforcement, correction, or help; e.g. (spelling), "Is this right?" . . . "I got it right, didn't I?" . . . "How do you spell . . .?"

In addition to whatever intrinsic learning benefit is derived from these behaviors, these students clearly will be attractive and rewarding to teach. The benefit-cost ratio relating pupil performance to teacher effort is likely to be high, compared to the payoff expected by teachers exerting equivalent effort for the kind of students typically considered mildly handicapped. In short, these normally achieving students don't require as much external structure or management; their demonstrated capacity for simultaneous, or at least rapidly shifting, processing at different levels of task engagement represents an emerging orderliness and self-regulation during academic work that prepares for and also must facilitate future as well as present learning.

When "basic skills" are still difficult puzzles rather than automatized responses, success in inventing or discovering increasingly efficient algorithms is similarly assisted by the 
ability to overview one's problem solving behavior without losing place or tempo. For example, without direct prompting or instruction, normal preschoolers given a simple addition task (counting blocks for each addend, then combining sets and recounting) were observed by Groen and Resnick (1977) to discover a more efficient algorithm (i.e, naming, then counting from largest addend) simply as a result of continued practice. As naming and physical counting out of blocks to match addends became more rapid, a portion of the process was transformed from being overt to covert, making problem solution more likely, faster, and certainly less cumbersome.

As a general rule, if responses become not only more accurate, but also faster (e.g., see Ackerman \& Dykman, 1982; Chi \& Gallagher, 1982; Sternberg, 1981; Sternberg \& Wagner, 1982), a task-oriented excess capacity is generated that can be used to operate not on the response but rather on the procedure used to generate that response. Increasing automaticity of invented or discovered algorithms, whether "correct" or not, permits and encourages a kind of metacognitive housekeeping that aims to reduce mental effort by replacing or transforming components of old response generation procedures with more efficient ones.

\section{CBT and Effective Teaching}

Though a multi-element training technology suitable for general curricular use has not yet been developed, notable advances have been made. Egeland (1974), for example, was able to train impulsive children general "search-andscan" rules that led to improved performance on several laboratory tasks, but also appeared to improve performance on a test of reading comprehension 5 months after training.

Finally, Kendall and Wilcox (1980) created a more elaborate training program that resulted in practical (not merely statistically significant) improvements for a group of impulsive children. Their training program was unique because it combined, but differentiated, concrete (task-specific) and conceptual (generalized) training targets and procedures. Children were trained in a range of actual behavior and academic problem situations. Six training components used in both types of training consisted of modeling and practice in using verbal self-instructions but were made problem- or task-specific during concrete training, while they were presented more abstractly for application to problems in general during conceptual training. These components are:

1. Problem definition.

2. Problem approach.

3. Focusing attention.

4. Problem solution.

5. Self-reinforcement.

6. Coping with errors.
Some evidence has been developing also that supports not only the separability of cognitive and metacognitive processes (Slife, Weiss, \& Bell, 1985) but also the possibility of training strategic use of both during tasks requiring deliberate memorization (Ghatala, Levin, Pressley, \& Lodico, 1985). Recent studies by Ghatala and her colleagues have shown that even primary grade students can and will abandon ineffective strategies more rapidly and use appropriate strategies more effectively during deliberate memory tasks as a result of being trained to monitor and evaluate utility of task strategies.

In these studies, when students were prompted to use a detrimental strategy, its use probably resulted in an increase in response uncertainty; that is, the specific task demands became more, not less, problematic. Because high uncertainty results in more, not less, cognitive effort, detrimental procedures tended to be more spontaneously replaced by more natural (and inevitably more adequate) mnemonic strategies. On the other hand, when students had been prompted to use a strategy that was more efficient than one they might naturally generate, response uncertainty was reduced reliably and rapidly, relatively little mental effort was required, and a functional capacity "excess" was created with which the prompted strategy could be integrated with whatever mnemonic skills repertoire already existed.

Whereas these examples suggest that normally achieving, younger students benefit with relatively little external pacing and control, mildly handicapped students in upper elementary grades most often have been perceived as being incapable of functioning successfully without substantial teacher direction and environmental constraint. These perceptions typically lead to attempts to "overpower" slow learners with environmental management in the earliest stages of basic skills acquisition, rather than to "empower" them by systematic training in task self-management. When they are older, and their failure on more complex learning tasks is more dramatic, more heroic interventions are attempted, including CBT. These latter attempts possibly come too late to assist learners in developing an appropriately generic task management repertoire. Rather than bind metacognitive knowledge to the organization and structure of student ability to search, retrieve, and apply declarative and procedural knowledge about "basic" academic tasks, CBT then can be used only in very focal applications that serve to enhance specific (i.e., task) competence, but not generalized learning ability.

\section{Time and Technology}

Theoretical and empirical studies of CBT have contributed to new conceptual and methodological approaches to research and instructional design for children thought to be mildly handicapped. Moreover, this work, as a body, has tended to bring a strong theoretical basis to more behavior- 
ally derived techniques for decreasing impulsivity and increasing self-control. In their development to date, CBT methods have captured and uniquely organized what appear to be critical features of the most powerful instructional techniques.

In Walberg's (1984) summarization of data on a variety of general teaching approaches across student types and subject matter, his analyses show that manipulations of reinforcement contingencies-an intervention providing minimal structure by linking some pattern of antecedent and consequent events to responses-produced an average effect size of 1.20. Individualized tutoring, on the other hand, produced an average effect size of 2.00 .

Because individualized tutoring may not be feasible, Bloom (1984) compared Walberg's data to data from "mastery learning" studies in which teachers provided each student with sufficient time and corrective feedback over trials to assure performance at some targeted level. Although conventional approaches to instruction result in estimated effect sizes of about .50 , or .76 when enhanced by methods to assure "cognitive entry prerequisites," mastery learning alone resulted in an effect size of 1.00, and an effect size of 1.60 when enhanced by "cognitive entry prerequisites" (i.e., preskills and previous knowledge).

These data are particularly interesting in light of Palincsar and Brown's (1984) conclusion from a long series of studies that to be successful, cognitive training must "force" students to be cognitively active (engaged) during learning tasks, provide corrective feedback on appropriate use of trained tactics or strategies, and provide "instruction in why, when, and where such activities should be applied" (p. 122). Similarly, Bloom (1984) argued that as effort is made to assure that students possess ideas or skills necessary for learning new material:

. . . they become more positive about their ability to learn the subject, and they put in more active learning time than do control students. (p. 7)

From a direct instruction perspective, Carnine (1983) reported on two studies with similar implications for cumulative effects from structuring thinking during teaching. In the first, systematic preskills training of simple multiplication was compared with a no-preskills training condition in which each error was corrected and retaught as it occurred. Over 30\% more teaching time was required to reach criterion levels of performance without preskills training. Moreover, students trained in preskills transferred their knowledge more readily to a new set of items. In a second study of the effects of overt versus covert procedures for learning to read lists of phonetically simple words, the group that received instruction in component skills, including a "sounding out" operation, reached criterion 16 minutes faster than a group that received only "look-say" practice. On a transfer task, the component skills group averaged over three times as many correct responses.

These general investigations of teaching technology and its relationship to rate of learning support the general thesis that "good" instruction provides or elicits the amount of structure most likely to maximally reduce response uncertainty. Moreover, the amount of structure that must be provided by teaching methods appears to relate inversely to the cognitive maturity of prospective learners. Various well established techniques-overtly controlling incentives and attention to informative environmental cues (e.g., reinforcement), intensively guiding and monitoring attention to task and responding (e.g., tutoring), presenting "sufficient" response and feedback opportunities (e.g., direct instruction, mastery learning), assuring that necessary preskills are usable and available (e.g., some forms of direct instruction, mastery learning, cognitive training), and direct teaching of demonstrably useful overt behaviors related to task-specific performance (e.g, phonics instruction)—find common ground in their ability to make correct responding on a target task more probable by reducing response uncertainty or organizing information more efficiently for students than they are able to accomplish spontaneously on their own.

If these techniques can be applied systematically as part of a curriculum focused on enhancing cognitive-behavioral self-regulation during learning, the seemingly unresolvable problems of time and learning rate posed by slower learning, mildly handicapped students, whether in restrictive or less restrictive environments, may be addressed with new optimism.

\section{REFERENCES}

Abikoff, H. (1979). Cognitive training interventions in children: A review of a new approach. Journal of Learning Disabilities, 12, 65-77.

Ackerman, P. T., \& Dykman, R. A. (1982), Automatic and effortful information-processing deficits in children with learning and attention disorders. Topics in Learning \& Learning Disabilities, 2 (2), 12-22.

Ballard, K. D., \& Glynn, T. (1975). Behavioral self-management in story writing with elementary school age children. Journal of Applied Behavior Analysis, 8, 387-398.

Baroody, A. J. (1984). The case of Felicia: A young child's strategies for reducing memory during mental addition. Cognition \& Instruction, l(1), 109-116.

Becker, W. C. (1977). Teaching reading and language to the disadvantaged-what we have learned from field research. Harvard Educational Review, 47, 518-543.

Becker, W. C., \& Carnine, D. W. (1981). Direct instruction: A behavior theory model for comprehensive educational intervention with the disadvantaged. In S. W. Bijou \& R. Ruis (Eds.), Behavior modification: Contributions to education. Hillsdale, NJ: Lawrence Erlbaum.

Belmont, J. M., \& Butterfield, E. C. (1977). The instructional approach to developmental cognitive research. In R. Kail \& J. Hagen (Eds.), Perspectives on the development of memory and cognition (pp. 437481). Hillsdale, NJ: Lawrence Erlbaum.

Bissex, G. L. (1980). GYNS AT WRK. Cambridge, MA: Harvard University Press.

Bloom, B. S. (1984). The 2 sigma problem: The search for methods of group instruction as effective as one-to-one tutoring. Educational Researcher, 13(6), 4-16. 
Bookman, M. (1984). Spelling as a cognitive-developmental linguistic process: Implications for testing and teaching. Academic Therapy.

Borkowski, J. G., \& Cavanaugh, J. C. (1979). Maintenance and generalization of skills and strategies by the retarded. In N. R. Ellis (Ed.), Handbook of mental deficiency: Psychological theory and research (2nd ed.)(pp. 569-617). Hillsdale, NJ: Lawrence Earlbaum.

Borkowski, J. G., \& Konarski, E. A. (1981). Educational implications of efforts to train intelligence. Journal of Special Education, 15(2), 289305.

Bos, C. S. (1982). Getting past decoding: Assisted and repeated readings as remedial methods for learning disabled students. Topics in Learning \& Learning Disabilities, 1(4), 51-57.

Brown, A. L., Campione, J. C., \& Day, J. D. (1981). Learning to learn: On training students to learn from texts. Educational Researcher, 10(2), 14-21.

Brown, B. W., \& Saks, D. H. (April, 1983). An economic approach to measuring teachers' preferences in allocating time to students. Paper presented at the annual meeting of the American Educational Research Association, Montreal, Canada.

Carnine, D. (1983). Direct instruction: In search of instructional solutions for educational problems. In Interdisciplinary voices in learning disabilities and remedial education (pp. 1-66). Austin, TX: Pro-Ed.

Carpenter, T., Moser, J., \& Romberg, T. (Eds.) (1982). Addition and subtraction: A cognitive perspective. Hillsdale, $\mathrm{NJ}$ : Lawrence Erlbaum.

Chi, M. T. H., \& Gallagher, J. D. (1982). Speed of processing: A developmental source of limitation. Topics in Learning \& Learning Disabilities, 2(2), 23-32.

Cohen, S., \& deBettencourt, L. (1983). Teaching children to be independent learners: A step-by-step strategy. Focus on Exceptional Children, 16(3), 1-12.

Cook, L. (1981). Misspelling analysis in dyslexia: Observation of developmental strategy shifts. Bulletin of the Orton Society, 31, 123-134.

Corno, L., \& Mandinach, E. B. (1983). The role of cognitive engagement in classroom learning and motivation. Educational Psychologist, 18(2), 88-108.

Cullinan, D., Lloyd, J., \& Epstein, M. H. (1981). Strategy training: A structured approach to arithmetic instruction. Exceptional Education Quarterly, 2(1), 41-49.

Doyle, W. (1983). Academic work. Review of Educational Research, 53(2), 159-199.

Egeland, B. Training impulsive children in the use of more efficient scanning techniques. Child Development, 45, 165-171.

Engelmann, S. (1969). Preventing failure in the primary grades. Chicago: SRA.

Farnham-Diggory, S., \& Nelson, B. (1984). Cognitive analyses of basic school tasks. Applied Developmental Psychology, 1, 21-74.

Frederiksen, J. R., Warren, B. M., \& Roseberry, A. S. (1985). A componential approach to training reading skills: Part 1 . Perceptual units training. Cognition \& Instruction, 2(2), 91-130.

Frederiksen, N. (1984). Implications of cognitive theory for instruction in problem solving. Review of Educational Research, 54(3), 363-407.

Frith, U. (1980). Cognitive processes in spelling. London: Academic Press.

Gerber, M. M. (1983). Learning disabilities and cognitive strategies: A case for training or constraining problem solving? Journal of Learning Disabilities, 16(5), 255-260.

Gerber, M. M. (1984a). The Department of Education's Sixth Annual Report to Congress on P. L. 94-142: Is congress getting the full story? Exceptional Children, 51(3), 209-224.

Gerber, M. M. (1984b). Investigations of orthographic problem-solving ability in learning disabled and normally achieving students. Learning Disability Quarterly, 7, 157-164.

Gerber, M. M. (1984c). Techniques to teach generalizable spelling skills. Academic Therapy, 20(1), 49-58.

Gerber, M. M. (1985). Spelling as concept-driven problem solving. In B. Hutson (Ed.), Advances in reading/language research (Vol. 3) (pp. 39-75). Greenwich, CT: JAI Press.

Gerber, M. M. (in press). Generalization of spelling strategies by LD students as a result of contingent imitation/modeling and mastery criteria. Journal of Learning Disabilities.

Gerber, M. M., \&.Niemann, C. (in preparation). Self-monitoring and acquisition of new academic skills.
Gerber, M. M., \& Semmel, M. I. (1985). The microeconomics of referral and reintegration: A paradigm for evaluation of special education. Studies in Educational Evaluation, 11, 13-29.

Gettinger, M. (1984a). Achievement as a function of time spent in learning and time needed for learning. American Educational Research Journal, $21(3), 617-628$

Gettinger, M. (1984b). Applying learning principles to remedial spelling instruction. Academic Therapy, 20(1), 41-48.

Gettinger, M., \& Lyon, M. A. (1983). Predictors of the discrepancy between time needed and time spent in learning among boys exhibiting behavior problems. Journal of Educational Psychology, 75(4), 491499.

Gettinger, M., \& White, M. A. (1979). Which is the stronger correlate of school learning? Time to learn or measured intelligence? Journal of Educational Psychology, 71, 405-412.

Ghatala, E., Levin, J. R., Pressley, M., \& Lodico, M. G. (1985). Training cognitive strategy monitoring in children. American Educational Research Journal, 22(2), 199-215.

Good, T. L. (1983). Classroom research: A decade of progress. Educational Psychologist, 18(3), 127-144.

Graham, S. (1983). The effect of self-instructional procedures on LD students' handwriting performance. Learning Disability Quarterly, 6(2), 231-234

Graham, S., \& Freeman, S. (1985). Strategy training and teacher vs. student-controlled study conditions: Effects of learning disabled students' spelling performance. Learning Disability Quarterly, 8(4), 267 274.

Grimm, J. A., Bijou, S. W., \& Parsons, J. A. (1973). A problem solving model for teaching remedial arithmetic to handicapped young children. Journal of Abnormal Child Psychology, 1, 26-39.

Groen, G., \& Resnick, L. B. (1977). Can preschool children invent addition algorithms? Journal of Educational Psychology, 69, 645-652.

Hall, R. J. (1980). Cognitive behavior modification and information-processing skills of exceptional children. Exceptional Education Quarterly, 1(1), 9-15.

Hallahan, D. P., Hall, R. J., Ianna, S. O., Kneedler, R. D., Lloyd, J. W., Loper, A. B., \& Reeve, R. E. (1983). Summary of research findings at the University of Virginia Learning Disabilities Research Institute. Exceptional Education Quarterly, 4(1), 95-114.

Hallahan, D. P., \& Reeve, R. (1980). Selective attention and distractibility In B. Keogh (Ed.), Advances in special education (Vol. 1) (pp. 141181). Greenwich, CT: JAI Press.

Hallahan, D. P., \& Sapona, R. (1983). Self-monitoring of attention with learning-disabled children: Past research and current issues. Journal of Learning Disabilities, 16(10), 616-620.

Harris, K. R. (1982). Cognitive-behavior modification: Application with exceptional students. Focus on Exceptional Children, 15(2), 1-16.

Harris, K. R., \& Graham, S. (1985). Improving learning disabled students' composition skills: Self-control strategy training. Learning Disability Quarterly, 8, 27-36.

Henderson, E. H., \& Beers, J. W. (Eds.). (1980). Developmental and cognitive aspects of learning to spell-a reflection of word knowledge. Newark, DE: International Reading Association.

Karweit, N., \& Slavin, R. E. (1981). Measurement and modeling choices in studies of time and learning. American Educational Research Journal, 18(2), 157-171.

Kauffman, J. M., \& Hallahan, D. P. (1979). Learning disability and hyperactivity. In B. B. Lahey \& A. E. Kazdin (Eds.), Advances in child clinical psychology (Vol. 2) (pp. 71-105). New York: Plenum.

Kosiewicz, M. M., Hallahan, D. P., Lloyd, J. W., \& Graves, A. W. (1982). Effects of self-instruction and self-correction procedures on handwriting performance. Learning Disability Quarterly, 5, 71-78.

Kendall, P. C., \& Wilcox, L. E. (1980). Cognitive-behavioral treatment for impulsivity: Concrete versus conceptual training in non-self-controlled problem children. Journal of Consulting \& Clinical Psychology, $48,80-91$.

Lloyd, J. (1975). The pedagogical orientation: An argument for improving instruction. Journal of Learning Disabilities, 8(2), 74-78.

Lloyd, J. (1980). Academic instruction and cognitive behavior modification: The need for attack strategy training. Exceptional Education Quarterly, $I(1), 53-63$ 
Lloyd, J., Cullinan, D., Heins, E. D., \& Epstein, M. H. (1980). Direct instruction: Effects on oral and written language comprehension. Learning Disability Quarterly, 3(4), 70-76.

Lloyd, J. W., Saltzman, N. J., \& Kauffman, J. M. (1981). Predictable generalization in academic learning as a result of preskills and strategy training. Learning Disability Quarterly, 4, 203-216.

Lovitt, T. (1975). Specific research recommendations and suggestions for practitioners. Journal of Learning Disabilities, 8, 504-517.

Lovitt, T. C., \& Curtiss, K. A. (1968). Effects of manipulating an antecedent event on mathematics response rate. Journal of Applied Behavioral Analysis, 1, 329-333.

Nulman, J. H., \& Gerber, M. M. (1984). Improving spelling performance by imitating a child's errors. Journal of Learning Disabilities, 17, 328-333.

Palincsar, A. S., \& Brown, A. L. (1984). Reciprocal teaching of comprehension-fostering and comprehension-monitoring activities. Cognition \& Instruction, 1(2), 117-175.

Pflaum, S. W., \& Pascarella, E. T. (1980). Interactive effects of prior reading achievement and training in context on the reading of learning disabled children. Reading Research Quarterly, 16, 138-158.

Read, C. (1975). Children's categorization of speech sounds in English. Urbana, IL: National Council of Teachers of English.

Robin, A. L., Armel, S., \& O'Leary, K. D. (1975). The effects of self-instruction on writing deficiencies. Behavior Therapy, 6, 178-187.

Rooney, K. J., \& Hallahan, D. P. (1985). Future directions for cognitive behavior modification research: The quest for cognitive change. Remedial \& Special Education, 6(2), 46-51.

Rosenshine, B. (1983). Teaching functions in instructional programs. Elementary School Journal, 83, 335-351.

Russell, R. L., \& Ginsburg, H. P. (1984). Cognitive analysis of children's mathematics difficulties. Cognition \& Instruction, I(2), 217-244.
Samuels, S. J., (1979). The method of repeated readings. Reading Teacher, 32, 403-408.

Samuels, S. J., \& Miller, N. L. (1985). Failure to find attention differences between learning disabled and normal children on classroom and laboratory tasks. Exceptional Children, 51(5), 358-375.

Shavelson, R. J., \& Stern, P. (1981). Research on teachers' pedagogical thoughts, judgements, decisions, and behavior. Review of Educational Research, 51, 444-498.

Sheinker, A., Sheinker, J. M., \& Stevens, L. J. (1984). Cognitive strategies for teaching the mildly handicapped. Focus on Exceptional Children, $17(1), 1-15$.

Simon, H. A. (1973). The structure of ill-structured problems. Artificial Intelligence, 4, 181-201.

Slife, B. D., Weiss, J., \& Bell, T. (1985). Separability of metacognition and cognition: Problem solving in learning disabled and regular students. Journal of Educational Psychology, 77(4), 437-445.

Stemberg, R. J. (1981). Cognitive-behavioral approaches to the training of intelligence in the retarded. Journal of Special Education, 15(2), 165-183.

Sternberg, R. J., \& Wagner, R. K. (1982). Automatization failure in learning disabilities. Topics in Learning \& Learning Disabilities, 2(2), 1-11.

Stevens, R., \& Rosenshine, B. (1981). Advances in research on teaching. Exceptional Education Quarterly, 2(1), 1-9.

Walberg, H. J. (1984). Improving the productivity of America's schools. Educational Leadership, 41(8), 19-27.

Will, M. C. (1986). Educating children with learning problems: A shared responsibility. Exceptional Children, 52(5), 411-415.

Zigmond, N., \& Thornton, H. B. (April, 1985). Follow-up of postsecondary-age $L D$ graduates and dropouts. Paper presented at the annual meeting of the American Educational Research Association, Chicago.

\section{Professional update}

\section{NEW BOOKS}

\section{Alternatives: A Family Guide to Legal and Financial Planning for the Disabled}

\section{Mark Russell}

As an attorney with a mentally handicapped brother, the author has written Alternatives to address this specialized need for families with disabled members. It addresses the unavoidable question of what will happen to the child after the parents' death.

The Estates, Gifts and Trusts Journal called the book "an admirable work and possibly the first comprehensive piece to concentrate on the difficult estate problems created by a disability." Choice Magazine stated that the book simplifies a complicated process for its readers: ". . . trusts, taxes and government benefits are well and simply presented. . . " And the Library Journal agreed that "explanations of complex legal and government requirements are clearly written for the layperson."

Among the questions posed are: Does my child need a legal guardian? Am I taking advantage of all the possible medical deductions and credits I am entitled to receive? What is the easiest way of obtaining medical insurance for my handicapped child? The author suggests that his book be shared with the family's attorney.

The 194-page book is available from First Publications, P.O. Box 1832, Evanston, IL 60204.

\section{The Right to Grow Up: An Introduction to Adults with Developmental Disabilities}

\section{Jean Ann Summers, Editor}

This new book tackles the question: What happens to developmentally disabled individuals when they grow up? The book acknowledges the distinctive needs of these persons and stresses the importance of providing services throughout their lives. To assure proper services, the editor points up three important considerations: the particular nature of their needs, the specific services that will be required to meet those needs, and the legal and administrative mechanisms to ensure availability of the needed services.

Contributors to the book cover the areas of transition to adulthood; sexuality, marriage, and parenthood; the later years; residential and vocational services; leisure and recreation; independent living; applicable federal laws, administration, and policy making; among other topical concerns.

This 340-page paperback is published by Paul $\mathrm{H}$. Brookes Publishing Co., Baltimore, MD. 